\title{
Antinociceptive and Relaxant Effects of Aqueous Extract of the Aerial Part of Ziziphora clinopodioides
}

\author{
Seyyed Majid Bagheri, Hamid Mohamadsadeghi
}

\section{Seyyed Majid Bagheri ${ }^{1,2, *}$, Hamid Mohamadsadeghi ${ }^{1}$}

\author{
'Department of Physiology, Shahid \\ Sadoughi University of Medical \\ Sciences, Yazd, IRAN. \\ ${ }^{2}$ Neurobiomedical Research Center, \\ Shahid Sadoghi University of Medical \\ Sciences, Yazd, IRAN. \\ Correspondence

\section{Seyyed Majid Bagheri} \\ 'Department of Physiology, Shahid \\ Sadoughi University of Medical \\ Sciences, Yazd, IRAN. \\ ${ }^{2}$ Neurobiomedical Research Center, \\ Shahid Sadoghi University of Medical \\ Sciences, Yazd, IRAN. \\ Phone: +983518203410-17 \\ Email: boss_bagheri@yahoo.com \\ History \\ - Submission Date: 02-07-2019; \\ - Review completed: 09-08-2019; \\ - Accepted Date: 14-09-2019.
}

DOI : 10.5530/ijcep.2019.6.3.25

\section{Copyright}

(C) 2019 Phcog.Net. This is an openaccess article distributed under the terms of the Creative Commons Attribution 4.0 International license.

\begin{abstract}
Background and Aim: Plants from Iranian biomes, such as Ziziphora clinopodioides has been used as natural medicines by local populations in the treatment of several diseases such as asthma and stomachache and hypertension. In this study we investigated the antinociceptive and spasmolytic effects of aerial parts of aqueous extract of Ziziphora clinopodioides (APAEZC). Methods: The extract was injected to male mice $15 \mathrm{~min}$ before the onset of experiments intraperitoneally. Writhing and hot-plate tests were applied to study the analgesic effect of APAEZC and compared with that of diclofenac sodium $(30 \mathrm{mg} / \mathrm{kg}$, i.p.) or morphine $(8 \mathrm{mg} / \mathrm{kg}$, i.p). For evaluating spasmolytic effect of the extract, $5 \mathrm{~cm}$ of smooth muscle from ileum of rats were removed and set up for recording the isotonic contractions. Control contractions were obtained by adding acetylcholine $\left(10^{-4} \mathrm{M}\right)$ to each tissue preparation and the spasmolytic action of different APAEZC concentrations $(0.1,0.2$ and $0.3 \%$ ) on maximum contraction induced by acetylcholine were evaluated 5 min later. Results: APAEZC exhibited a significant $(P<0.05)$ antinociceptive effect in both chronic and acute pain in all doses in mice and also showed a significant spasmolytic effect at dose $0.2(P<0.05)$ and dose $0.3 \% \quad(P<0.01)$. Conclusion: The findings of this study indicated that APAEZC have analgesic and relaxant effects. These results support the traditional claim of Ziziphora clinopodioides as an antinociceptive and antispasmodic therapeutic agent.

Key words: Ziziphora clinopodioides, Pain, Spasmolytic, Hot plate, Writhing test
\end{abstract}

\section{INTRODUCTION}

In humans, pain has injurious effects on sleep, cognitive abilities such as learning, ${ }^{[1]}$ attention ${ }^{[2]}$ and the capacity for work. ${ }^{[3]}$ Pain is caused following tissue or peripheral nerve damage or injuries to different parts of the central nervous system in humans and animals. Although there are different effective analgesic drugs and widely used, but these drugs have side-effects and making their clinical use problematic. ${ }^{[4]}$ In the recent years, tendency to herbal medicine has been increased and people have recognized and used of many cultivated or wild plants. Plant products have less toxic effects than synthetic ones and are a good source for novel therapeutic agents. ${ }^{[5]}$ Ziziphora clinopodioides (Mountains' Kakoty) from the genus of Ziziphora and family of Lamiaceae is a traditional medicinal plant, which is a semi-perennial shrub-like plant that grows on low hills, grassland and arid slopes and is widely distributed in China, Mongolia, Turkey, Iran, Kazakhstan and Kyrgyzstan. ${ }^{[6]}$ It is mainly used for the treatment of heart disease, high blood pressure, asthma hyperhidrosis, palpitation insomnia, edema, cough, bronchitis, lung abscess and other diseases in these traditional medicines. ${ }^{[7]}$ In Iranian traditional medicine, it is used as sedative, gastric pain, stomachache carminative and the dried aerial parts of this plant are used in cooking and other dairy products as additive and giving aroma to food. ${ }^{[8]}$ Different studies showed that the main constituents of the plant essential oil were pulegone, neomenthol, menthone, 1, 8-cineole, thymol, carvacrol, Linalool and piperitone. ${ }^{[8]}$ New studies demonstrated that Ziziphora clinopodioides has antibacterial and antioxidant activities. ${ }^{[9]}$ In a research, Ghafari $e t$ al. showed the anti-inflammatory effect of Ziziphora clinopodioides. ${ }^{[10]}$ They found that the essential oil of this plant inhibits acetic acid toxic reactions in the rats bowl and this is due to the inhibition of oxidative stress of cellular texture. The present study was performed for examining the folkloric claims of traditional regarding the analgesic and relaxant effects of this medicinal plant.

\section{MATERIALS AND METHODS}

\section{Extract Preparation}

The plant (aerial parts) used for the present study was collected locally in the Ghochan (in north Khorasan province-Iran). Plant was identified by Dr. Abbas Zarezadeh in the Department of Botany in Agricultural Research Center (Yazd Iran). The powder $(400 \mathrm{~g})$ was extracted exhaustively in a soxhlet apparatus with distilled water $(180 \mathrm{ml})$. The extract was filtered using filter paper and then 
concentrated in vacuo at $40^{\circ} \mathrm{C}$ using a Rotary evaporator. The residues obtained were stored until used.

\section{Animals}

For evaluation of acute and chronic antinociceptive effect of extract, 60 Swiss male albino mice $(25-30 \mathrm{~g})$ were used. We also used 20 rats for determination of spasmolytic effect of the extract. All animals were normal and healthy and kept in automatically controlled temperature conditions $\left(23 \pm 2^{\circ} \mathrm{C}\right)$, in $12 \mathrm{~h}$ light-dark cycles, with standard food for rodents and tape water "ad libitum". $48 \mathrm{hr}$ prior to the experiments, the animals were kept in the laboratory and $8 \mathrm{hr}$ prior to the experiment, they were deprived of food. All the experimental animals were treated following the Ethical Principles and Guidelines for Scientific Experiments on Animals (1995) formulated by The Swiss Academy of Medical Sciences and the Swiss Academy of Sciences. All experimental protocols were approved by the Ethics Committee of Shahid Sadoughi University of Medical Sciences.

\section{Drugs and Treatments}

The drugs used were acetylcholine iodide (from the Sigma Chemical Company, St. Louis, USA), stored at $-4^{\circ} \mathrm{C}$ and diluted to the desired concentrations in $0.9 \%$ saline just before use. Glucose, $\mathrm{NaCl}, \mathrm{KCl}, \mathrm{CaCl}_{2}$ $.2 \mathrm{H}_{2} \mathrm{O}, \mathrm{MgCl}_{2} \cdot 6 \mathrm{H}_{2} \mathrm{O}, \mathrm{NaHCO}_{3}$ and $\mathrm{NaH}_{2} \mathrm{PO}_{4}$ was acquired from Merck KGA, Darmstadt, Germany. The standard drug morphine sulphate $(8 \mathrm{mg} / \mathrm{kg})$ used in hot plate test and diclofenac sodium $(30 \mathrm{mg} / \mathrm{kg})$ in writhing and licking tests were administered intraperitoneally $15 \mathrm{~min}$ before the experiments while the animals in control group received vehicle orally (normal saline). APAEZC was intraperitoneally administered to the test animals $30 \mathrm{~min}$ before the experiments at the doses of 100,200 and $300 \mathrm{mg} / \mathrm{kg}$ body weight in both the chemical-induced and heat-induced pain models.

\section{Hot-plate Test}

The hot-plate test was carried out according to the method previously described. ${ }^{[1]}$ Briefly, before the initial of experiment, mice were habituated to a Plexiglas cylinder for $5 \mathrm{~min}$. In these experiments, the hot-plate apparatus was maintained at $54 \pm 0.1^{\circ} \mathrm{C}$. Animals were placed into an acrylic cylinder (20 cm in diameter) on the heated surface and the time (in seconds) between placement and licking of their hind paws or jumping (whichever occurred first), was recorded as the response latency (reaction time). Each mouse served as its own control. A 45-s cut-off was used to prevent tissue damage. After baseline behavior tests, mice were immediately administered with drugs. The animals were intraperitoneally (i.p.) received vehicle (saline, $10 \mathrm{ml} / \mathrm{kg}$ ), the extract $(100,200$ and $300 \mathrm{mg} / \mathrm{kg}$ ) and morphine $(8 \mathrm{mg} / \mathrm{kg}) 15 \mathrm{~min}$ before the test. The reaction time of each mouse was again valuated at 15, 30, 45 and 60, min after treatment. Antinociception was expressed by mean percentage maximum possible effect (\%MPE). The \%MPE was calculated using the following formula:

$$
\% \mathrm{MPE}=\frac{\text { Test latency }- \text { Control latency }}{\text { Cut off }- \text { Control latency }} \times 100
$$

\section{Acetic Acid-induced Writhing Test}

The abdominal constriction test described by Bagheri et al. ${ }^{[12]}$ was used to measure the analgesic activity of the extract. Male mice pre-treated with extract $(100,200$ and $300 \mathrm{mg} / \mathrm{kg})$ or diclofenac $(30 \mathrm{mg} / \mathrm{kg}) .15 \mathrm{~min}$ later, all mice were treated with intraperitoneal injection of $0.6 \%$ acetic acid to cause a typical stretching response. Five min after acetic acid injection, mice were kept in individual cages and writhing or stretching of each mouse was counted for a period of $30 \mathrm{~min}$ by a blinded individual. The analgesic effect was measured by calculating the mean reduction in the number of abdominal constrictions for each drug as compared to saline control. Percentage inhibition of writhing was calculated by using the following formula:

$$
\% \text { Inhibition }=\frac{\begin{array}{l}
\text { Mean number of writhes }(\text { control })- \\
\text { Mean number of writhes }(\text { test })
\end{array}}{\text { Mean writhes }(\text { control })} \times 100
$$

\section{Assessment of Spasmolytic Effect}

In this study $0.1,0.2$ and $0.3 \%$ extract was examined for their spasmolytic action. Experiments were performed as described previous reported by Bagheri et al. ${ }^{[13]}$ Briefly, adult male Albino rats were sacrificed by cervical dislocation. Segments of ileum (5 cm in length), were excised, flushed their contents and trimmed them of mesentery. The specimens were conserved in Tyrode's solution until the onset of experimental procedure. The tissue sample was fixed at the bottom of the internal chamber of an organ bath containing $50 \mathrm{ml}$ Tyrode's solution in the axis of its longitudinal muscle and its opposite end was tightly tied to the isotonic transducer lever with a piece of trade, the chamber was maintained at $37^{\circ} \mathrm{C}$ and bubbled with $95 \% \mathrm{O}_{2}$ and $5 \% \mathrm{CO}_{2}$. Isotonic responses were recorded using an isotonic Transducer (T2) and an ocillograph recording system (the bioscience 400 Series Washington ocillograph). Then, it was allowed to stabilize for $15 \mathrm{~min}$ prior to the addition of drug and washed out in 30 min intervals by a fresh Tyrode's solution. Control contractions were obtained by adding acetylcholine (10-4M) to each tissue preparation and the spasmolytic action of different extract $(0.1,0.2$ and $0.3 \%)$ on maximum contraction induced by acetylcholine were evaluated $5 \mathrm{~min}$ later. Tissue specimens then were washed out by Tyrode's solution and incubated in the separate sets of experimental solutions at least for $20 \mathrm{~min}$.

\section{Statistical Analysis of Data}

Results were expressed as mean \pm standard error (S.E.M) and statistically assessed by Two-way ANOVA, followed by post hoc Tukey's test using Graph pad prism version 5. A value of $P<0.05$ was considered as significant.

\section{RESULTS}

\section{Hot-plate Test}

Latency responses for animals in different groups are shown in Table 1. The latencies for time 0 (base line latency) were statically analyzed by one-way ANOVA and there was no significant difference between the groups. Our data analysis showed that all doses of extract have a maximum analgesic effect against thermally induced pain at $15 \mathrm{~min}$ $(P<0.01)$. The most effective dose of extract was $300 \mathrm{mg} / \mathrm{kg}$ and its maximum

\begin{tabular}{ccccccc} 
Table 1: Hot plate latency responses of animals in different groups $(\boldsymbol{n}=6)$. \\
$\begin{array}{ccccccc}\text { Latency } \\
\text { time (s) }\end{array}$ \\
Group & $\begin{array}{c}\text { Dose } \\
(\mathrm{mg} / \mathrm{kg})\end{array}$ & 0 & 15 & 30 & 45 & 60 \\
\hline Control & - & $9.7 \pm 2.1$ & $10.3 \pm 3.2$ & $11.6 \pm 1.6$ & $11.4 \pm 2.8$ & $11.1 \pm 2.5$ \\
APAEZC & 100 & $8.2 \pm 1.6$ & $12 \pm 3.9^{*}$ & $11.3 \pm 2.6$ & $10.3 \pm 2.4$ & $9.3 \pm 2.3$ \\
& 200 & $8.6 \pm 0.9$ & $14.1 \pm 3.2^{*}$ & $11.9 \pm 2.5$ & $10.9 \pm 2.8$ & $9.1 \pm 3.1$ \\
& 300 & $9.1 \pm 1.5$ & $15.7 \pm 3.4^{* *}$ & $13.6 \pm 2.9^{*}$ & $11.7 \pm 1.7$ & $10.4 \pm 2.1$ \\
Morphine & 8 & $9.5 \pm 1.6$ & $17.9 \pm 3.4^{* *}$ & $15.3 \pm 4.2^{* *}$ & $13.7 \pm 3.7^{*}$ & $12.8 \pm 4.8$
\end{tabular}

The analysis of latency times of different groups. The baseline time of each group is considered as control and other times compare with baseline. ${ }^{\star} P<0.05,{ }^{* *}, P<0.01$ 


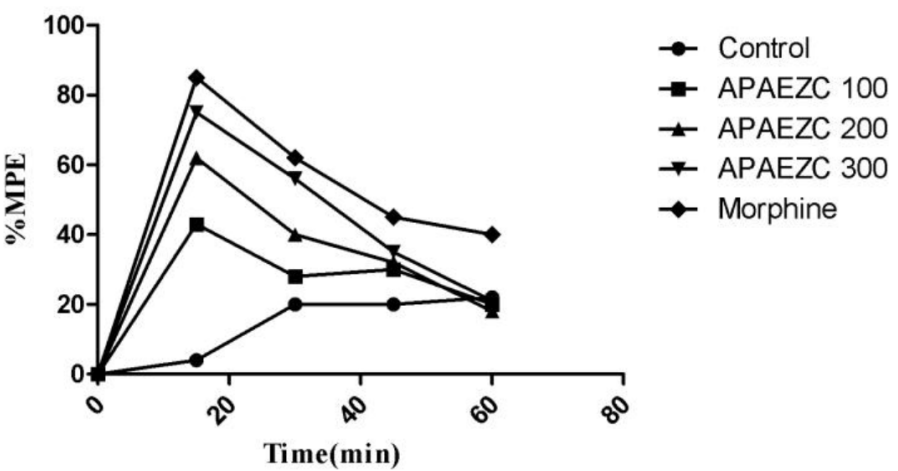

Figure 1: The percentage of Maximum Possible Effect (\%MPE) of different treatments on acute pain inhibition at different time points in hot plate test $(n=6)$.

Table 2: The effect of APAEZC on acetic acid-induced writhing in mice $(n=6)$.

\begin{tabular}{cccc} 
Group & Dose $(\mathrm{mg} / \mathrm{kg})$ & $\begin{array}{c}\text { Number of } \\
\text { writhing }\end{array}$ & $(\%)$ Inhibition \\
\hline Control & - & $110.4 \pm 2.1$ & - \\
APAEZC & 100 & $72.9 \pm 1.6$ & 34.0 \\
& 200 & $66.8 \pm 1.5^{*}$ & 39.5 \\
& 300 & $45.9 \pm 4.1^{* *}$ & 58.4 \\
Sodium Diclofenac & 30 & $37.9 \pm 2.9$ & 65.7
\end{tabular}

${ }^{*} p<0.05$ and ${ }^{* *} p<0.01$ compare to the control group. Values are the mean \pm SEM for at least 6 mice per group.

effect was observed $15 \mathrm{~min}$ after drug administration. As shown in Figure 1, the \%MPE at 15 min post treatment time point for all doses of extract was significantly greater than that of the control group.

\section{Acetic Acid-Induced Writhing Test}

The effect of extract on acetic acid induced writhing is presented in Table 2. All doses of the extract reduced acetic acid-induced writhing significantly. These results showed that with increasing the extract concentration, the number of writhing was decreased. The smallest dose of the extract showed relatively moderate analgesic activity with $34 \%(P<0.05)$ inhibition of acetic acid-induced writhing compared to controls and the extract 200 and 300 showed $39.5 \%$ and $58.4 \%$ inhibition and lower to that of the standard drugs.

\section{Spasmolytic Effect of Extract on lleum Contraction Induced by Acetylcholine}

In this study, we investigated the relaxant effect of the extract in three doses $(0.1 \%, 0.2 \%$ and $0.3 \%)$. Our findings showed that the extract in concentrations of 0.2 and 0.3 significantly reduced acetylcholine (10-4M) induced contractions the percentage of contraction of extract was $55.1 \pm 6.12$ and $23 \pm 4.4$ respectively vs. $100 \pm 0.00,(P<0.01$, Figure 2$)$.

\section{DISCUSSION}

Our findings indicated that the extract reduces the number of acetic acid induced writhes in a dose-dependent manner comparable to that of the sodium diclofenac. The analgesic effect of the extract may be due either to its action on visceral receptors sensitive to acetic acid or to the inhibition of production/action of prostaglandins. ${ }^{[14]}$ In the other hands, hot-plate test is one of the most common tests for monitoring the phasic nociceptive responses to a noxious heat stimulus of high intensity. ${ }^{[15]}$

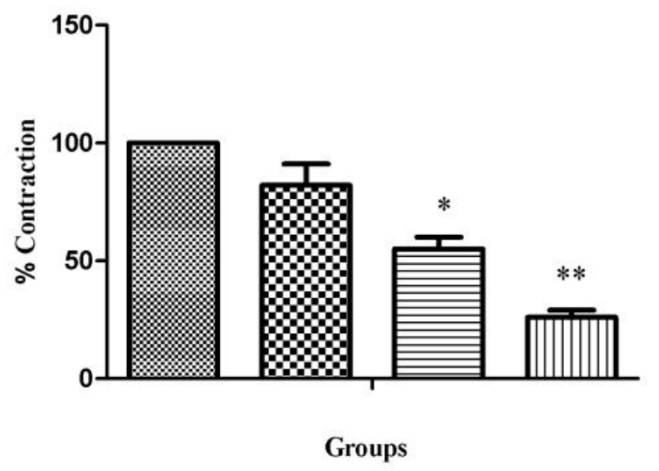

Figure 2: Spasmolytic effect of APAEZC on acetylcholine-induced contractions in the isolated rat's ileum.

*indicates the significant difference $(p<0.05)$ and ** indicates the significant difference $(p<0.01)$ as compared to the control group.

Pain induced by this thermal noxious stimulus is specific for centrally mediated antinociception ${ }^{[16]}$ and is thought to involve opioid pain inhibitory pathways. ${ }^{[17]}$ In the hot plate test, a significant effect of the APAEZC at all doses was obtained $15 \mathrm{~min}$ after treatment and the overall analgesic pattern of the most effective doses $300 \mathrm{mg} / \mathrm{kg}$. Therefore, the analgesic effect of the APAEZC in hot plate test may be related to the opioid pain inhibitory pathways. The fact that the extract produced its analgesic action in both tonic and phasic nociceptive models is indicative that it may possess both central and peripheral antinociception. One possible mechanism of action for the extract could be related to lipoxygenase and/or cyclooxygenase in the arachidonic acid cascade at the peripheral route. ${ }^{[18]}$ Moreover, the antinociceptive activity of APAEZC may be due to the terpenoids compounds which are present in a high percentage in Ziziphora clinopodioides 8. Recent reports on the therapeutic effects of plant extracts have ascribed the analgesic activities exerted by presence of terpenoids compounds. ${ }^{[19]}$ Recent works have demonstrated that monoterpenes may present important pharmacological properties including antimicrobial, antioxidant, analgesic and antitumoral and antispasmodic activities. ${ }^{[20]}$ Some of these monoterpenoids such as carvacrol, menthol and limonene have analgesic and ant inflammatory effects. ${ }^{[21]}$ In this study we also examined the relaxant potential of the extract on ileum isolated in animal model. The relaxant effect of the extract showed a significant correlation between the spasmolytic effect and the concentration. Various mechanisms are involved in gastrointestinal smooth muscle relaxation. These include the blocking action on excitatory such as cholinergic, histaminergic, adrenergic, purinergic, GABAergic and/or nitric oxide. ${ }^{[13]}$ In previous study, researchers demonstrated that Ziziphora clinopodioides extract exhibits vasodilating properties that are mediated by inhibition of extracellular $\mathrm{Ca} 2+$ influx and also by the opening of voltage- dependent $\mathrm{K}+$ channels. ${ }^{[22]}$ In China, Ziziphora clinopodioides is traditionally used for the treatment of hypertension, fever, edema, heart disease, neurasthenic, insomnia, gastrointestinal diseases, tracheitis, lung abscess and hemorrhoids. In Iranian and Turkish folk medicines, it is used as gastrointestinal disorders asthma and carminative. May be therapeutic and helpful effect of the extract on some these disorders such as asthma and hypertension due to its relaxant effect on smooth muscle and can be used as a relieving drug for the treatment of these diseases.

\section{CONCLUSION}

In conclusion, the results of the present study showed an analgesic and relaxant effects for the extract. However, the exact mechanism of these effects remains to be clarified and further investigations including chronic 
toxicity studies and activity-guided fractionation must be performed in order to assess the active compounds of the extract.

\section{ACKNOWLEDGEMENT}

This research was supported by the foundation of Shahid Sadoughi University of Medical Sciences and Health Services, Yazd, Iran.

\section{CONFLICT OF INTEREST}

We certify that no actual or potential conflict of interest related to this article exists.

\section{ABBREVIATIONS}

APAEZC: Aerial part of aqueous extract of Ziziphora clinopodioides.

\section{REFERENCES}

1. Budge C, Carryer J, Boddy J. Learning from people with chronic pain: Messages for primary care practitioners. J Fam Health. 2012;4(4):306-12.

2. Kluetsch RC, Schmahl C, Niedtfeld I, Densmore M, Calhoun VD, Daniels J, et al. Alterations in default mode network connectivity during pain processing in borderline personality disorder. Archives Gen Psychiatry. 2012;69(10):993-1002.

3. Lee KC, ChiuTT, Lam TH. The role of fear-avoidance beliefs in patients with neck pain: Relationships with current and future disability and work capacity. Clin Rehabil. 2007;21(9):812-21

4. Donck VA, Vranken JH, Puylaert M, Hayek S, Mekhail N, Zundert VJ. Intrathecal Drug Administration in Chronic Pain Syndromes. Pain Pract: The Official Journal of World Institute of Pain. 2013.

5. Kadir ASL, Yaakob H, Mohamed ZR. Potential anti-dengue medicinal plants: A review. J Nat Med. 2013;67(4):677-89.

6. Tian S, Shi Y, Yu Q, Upur H. Determination of oleanolic acid and ursolic acid contents in Ziziphora clinopodioides Lam. by HPLC method. Pharmacogn Mag. 2010;6(22):116.

7. Tian S, Shi Y, Zhou X, Ge L, Upur H. Total polyphenolic (flavonoids) content and antioxidant capacity of different Ziziphora clinopodioides Lam. extracts. Pharmacogn Mag. 2011;7(25):65.

8. Beikmohammadi M. The evaluation of medicinal properties of Ziziphora clinopodioides. World Appl Sci J. 2011:12(9):1635-8.
9. Salehi P, Sonboli A, Eftekhar F, Nejad-Ebrahimi S, Yousefzadi M. Essential oil composition, antibacterial and antioxidant activity of the oil and various extracts of Ziziphora clinopodioides subsp. rigida (BOISS.) RECH. f. from Iran. Biol Pharm Bull. 2005;28(10):1892-6.

10. Ghafari H, Yasa N, Mohammadirad A, Dehghan G, Zamani M, Nikfar S, et al. Protection by Ziziphora clinopoides of acetic acid-induced toxic bowel inflammation through reduction of cellular lipid peroxidation and myeloperoxidase activity. Hum Exp Toxicol. 2006;25(6):325-32.

11. Bagheri SM, Hedesh ST, Mirjalili A, Dashti-R MH. Evaluation of Anti-inflammatory and Some Possible Mechanisms of Antinociceptive Effect of Ferula assafoetida Oleo Gum Resin. J Evid Based Complementary Altern Med. 2015. 2156587215605903.

12. Bagheri S, Dashti-R M, Morshedi A. Antinociceptive effect of Ferula assa-foetida oleo-gum-resin in mice. Res Pharm Sci. 2014;9(3):207.

13. Bagheri S, Hejazian S, Dashti-R M. The Relaxant Effect of Seed fs Essential Oil and Oleo-gum-resin of Ferula Assa-foetida on Isolated Rat's Ileum. Ann Med Health Sci Res. 2015:4(2):238-41.

14. Lawan A, Katsayal U, Yaro A. Anti-inflammatory and anti-nociceptive effects of the methanolic extract of the stem bark of Ficus vallis-choudae delile (Moraceae). Afr J Pharm Pharmacol. 2008;2(10):200-3.

15. Mandegary A, Sayyah M, Heidari MR. Antinociceptive and anti-inflammatory activity of the seed and root extracts of Ferula gummosa Boiss in mice and rats. DARU. 2004;12(2):58-62.

16. Magaii M, Anuka J, Abdu-Aguye I, Yaro A, Hussaini I. Preliminary studies on anti-inflammatory and analgesic activities of Securinega virosa (Euphorbiaceae) in experimental animal models. J Med Plants Res. 2007;2(2):39-44.

17. Besra S, Sharma R, Gomes A. Antiinflammatory effect of petroleum ether extract of leaves of Litchi chinensis Gaertn. x(Sapindaceae). J Ethnopharmacol. 1996;54(1):1-6.

18. Rajendra W, Armugam A, Jeyaseelan K. Toxins in anti-nociception and antiinflammation. Toxicon. 2004;44(1):1-17.

19. Amorim ACL, Lima CKF, Hovell AMC, Miranda ALP, Rezende CM. Antinociceptive and hypothermic evaluation of the leaf essential oil and isolated terpenoids from Eugenia uniflora L. (Brazilian Pitanga). Phytomedicine. 2009;16(10):923-8.

20. Quintans-Júnior L, Moreira JC, Pasquali MA, Rabie S, Pires AS, Schröder R, et al. Antinociceptive activity and redox profile of the monoterpenes. ISRN Toxicol. 2013;2013.

21. Guimarães AG, Quintans JS, Quintans Júnior LJ. Monoterpenes with analgesic activity-a systematic review. Phytother Res. 2013:27(1):1-15.

22. Senejoux F, Girard C, Kerram P, Aisa HA, Berthelot A, Bévalot F, et al. Mechanisms of vasorelaxation induced by Ziziphora clinopodioides Lam. (Lamiaceae) extract in rat thoracic aorta. J Ethnopharmacol. 2010;132(1):268-73.

Cite this article: Bagheri SM, Mohamadsadeghi H. Antinociceptive and Relaxant Effects of Aqueous Extract of the Aerial Part of Ziziphora clinopodioides. Int J Clin Exp Physiol. 2019;6(3):91-4. 